\title{
Method of Vortex Structure Identification in Axisymmetric Flow Field
}

Tomáš Hyhlík

Faculty of Mechanical Engineering, Czech Technical University in Prague. Technická 4, 16607 Praha 6. Czech Republic. E-mail: tomas.hyhlik@fs.cvut.cz

The article deals with the analysis of axisymmetric flow field from the point of view of vortex identification. The vortex is identified by using residual vorticity defined in the work [1]. The identification is based on the so called triple decomposition of motion [1]. The idea of vortex identification based on the residual vorticity which is easily applicable in the case of two dimensional flow field is extended to the case of axisymmetric flow. The analyses is based on the decomposition of velocity gradient tensor and on the search of so called basic reference frame which allows to examine clearly the kinematics of the flow field.

Keywords: Vortex Identification, Residual Vorticity, Tripple Decomposition, Axisymmetric Flow

\section{Acknowledgement}

The support from the Czech Science Foundation under Grant No. 14-08888S is gratefully acknowledged.

\section{References}

[1] KOLÁř́, V. (2007). Vortex identification: New requirements and limitation. In: International Journal of Heat and Fluid Flow, Vol. 28, pp. $638-652$

[2] HUNT, J.C.R, WRAY, A. A., MOIN, P. (1988). Eddies, streams, and convergence zones in turbulent flow. In: Center for Turbulence Research Report CTR-S88, pp. 193-208

[3] JEONG, J., HUSSAIN, F. (1995). On the identification of vortex. In: Journal of Fluid Mechanics, Vol. 332, pp. 185-214

[4] SKOČILASOVÁ, B., SKOČILAS, J. (2013). Simulation of Liquid Flow in Pipe. In: Manufacturing Technology, Vol. 13, No. 4, pp. 542-547

[5] SCHMID, P.J. (2010). Dynamic Mode Decomposition of Numerical and Experimental Data. In: Journal of Fluid Mechanics, Vol. 656, pp. 5-28

[6] HYHLÍK, T. (2015). Analysis of Synthetic Jet Flow by Means of Proper Orthogonal Decomposition and Dynamic Mode Decomposition Based on CFD Data. In: Proceedings of the $12^{\text {th }}$ International Symposium on Experimental and Computational Aerothermodynamics of Internal Flow, Lerici, Italy, ISAIF12-050 